\section{EFFECT OF AN EMS BODY-WORN CAMERA}

${ }^{1,2} \mathrm{JD} \mathrm{Ho}{ }^{*},{ }^{1,2} \mathrm{JL}$ Hick, ${ }^{1,2} \mathrm{PC}$ Nystrom, ${ }^{1,2} \mathrm{NS}$ Simpson, ${ }^{1,2} \mathrm{GA}$ Jones, ${ }^{2} \mathrm{JR}$ Miner. ${ }^{1}$ Hennepin EMS, Minneapolis, Minnesota, USA; ${ }^{2}$ Hennepin Healthcare Emergency Medicine, Minneapolis, Minnesota, USA

10.1136/bmjopen-2019-EMS.6

Background Body-Worn Cameras (BWCs) are not widely used in EMS. Preliminary study demonstrates a BWC effect on EMS performance. We hypothesize that there are other benefits yet to be discovered. We seek to identify other effects BWCs may have.

Method This is a 30 day observation study of 20 EMS providers wearing BWCs during duty shifts in February, 2018. Metrics tracked were citizen and employee complaints and comments related to the BWC, complaint investigation, and EMS personnel feedback and education related to BWC use.

Results There were no formal complaints made by citizens or employees related to BWC use. There were several neutral to positive comments made related to enhanced accuracy and transparency. There were 6 incidents that involved BWC footage requiring investigatory review. BWC immediate feedback allowed investigation closure within a few hours. In multiple cases, the BWC sparked meaningful discussion between EMS and the patient or their family. In at least 1 instance, there was de-escalation of an agitated bystander when the BWC was noticed.

Conclusion EMS use of BWCs encourages transparency, accuracy, and immediate feedback to EMS personnel. They are helpful in timely complaint resolution and continuing education. Their use appears to be well-received by the public and shows promise in de-escalating some agitated persons. We encourage more study of how BWCs can improve EMS patient care.

\section{REFERENCE}

1. Ho JD, Dawes DM, McKay EM, Taliercio JJ, White SD, Woodbury BJ, Sandefur MA and JR Miner. Effect of Body-Worn Cameras on EMS Documentation Accuracy: A Pilot Study. Prehosp Emerg Care, 2017;21:263-271.

Conflict of interest JD Ho serves as the medical director to Axon Enterprise, Inc. (manufacturer of body worn cameras) and owns stock in this company. Axon Enterprises supplied the cameras utilized in this study.

Funding Axon Enterprise, Inc. provided the cameras utilized in this study free of charge.

\section{BAG-VALVE-MASK VS LARYNGEAL MASK (I-GEL $\left.{ }^{\circledR}\right)$ DURING BASIC INSTRUMENTAL CPR WITH CAPNOGRAPHY MONITORING: PRELIMINARY RESULTS OF A RANDOMIZED CLUSTER TRIAL}

${ }^{1} \mathrm{FJ}$ Cereceda-Sánchez ${ }^{*},{ }^{2} \mathrm{~J}$ Molina-Mula, ${ }^{1} \mathrm{~J}$ Clar-Terradas, ${ }^{1} \mathrm{~A}$ Mascaró-Galmes, ${ }^{1} \mathrm{P}$ MonteroParís, ${ }^{1} \mathrm{~N}$ Martinez-Cuellar. 'SAMU 061 Baleares, Spain; ${ }^{2}$ Universidad de las Islas Baleares, Spain

\subsection{6/bmjopen-2019-EMS.7}

Background There is controversy about the optimal device for airway management during CPR. The International Liaison Committee on Resuscitation latest recommendations in $2015,{ }^{1}$ has raised doubts about the surveillance of the patients ventilated by advanced versus basic airways by means Bag-Valve-
Mask (BVM), also a recent randomized trial seems to corroborate this findings. ${ }^{2}$ The aim of our trial is to assess the quality of ventilation between Bag-Valve-Mask versus laryngeal Mask through capnography values obtained during Basic instrumental CPR.

Method Prospective cluster-randomized and open-label trial, realized in the Prehospital Emergency Medical Service 061 Balearic Islands, Spain. The Emergency Technicians of the 4 Basic Life Support ambulances (BLS) included in the trial were instructed in the use of capnography within BVM or I-Gel ventilation and randomized in two branches (BVM or I-Gel) in pairs. We exchanged the airway management for each group every 4 months.

Results During the first six months of the study, 15 patients were assisted by the BLS units, of these 8 were enrolled (4 in every branch) with enough capnography values during the initial 9 min of CPR. The mean \pm SD in the BVM branch was $13 \pm 8,41 \mathrm{mmHg}$; in case of the I-Gel branch was 24 $\pm 6,5 \mathrm{mmHg}$. Three patients were survivors, 2 with the I-Gel and 1 in the BVM.

Conclusion Prehospital airway management during CPR via I-Gel seems to provide better ventilation than BVM reflected by capnography values in the first data obtained from our sample.

\section{REFERENCES}

1. Callaway CW, Soar J, Aibiki M, Bottiger BW, Brooks SC, Deakin CD, et al. Part 4: Advanced Life Support: 2015 International Consensus on Cardiopulmonary Resuscitation and Emergency Cardiovascular Care Science With Treatment Recommendations. Circulation. 2015 Oct;132(16 Suppl 1):S84-145.

2. Jabre $P$, Penaloza $A$, Pinero $D$, Duchateau F-XX Borron SW, Javaudin $F$, et al Effect of bag-mask ventilation vs endotracheal intubation during cardiopulmonary resuscitation on neurological outcome after out-of-hospital cardiorespiratory arrest a randomized clinical trial. JAMA - J Am Med Assoc. 2018 Feb;319(8):779-87.

Conflict of interest None.

Funding This research received no specific grant from any funding agency in the public, commercial, or not-for-profit sectors.

\section{INJURIES AFTER TREATMENT WITH MECHANICAL CPR}

1,2 Louise Milling*, ${ }^{2}$ Søren Mikkelsen, ${ }^{1}$ Birgitte Schmidt Astrup. ${ }^{1}$ Institute of Forensic Medicine, University of Southern Denmark, Denmark; ${ }^{2}$ Department of Anesthesiology, Odense University Hospital, Denmark

\subsection{6/bmjopen-2019-EMS.8}

Background In later years studies concerning injuries as a result of mechanical CPR (mech-CPR) have emerged. A characterization of these injuries could be of importance in a clinical setting, where quick and targeted diagnosis of injuries may prove to be lifesaving. The aim of this study was to characterize potential visceral injuries as a result of mech-CPR.

Method A total of 50 deceased from the Region of Southern Denmark in the years 2014-2018 were included in this retrospective case series. All were autopsied - either in a hospital or forensic setting. Exclusion criteria were trauma, age below 18 years or pregnancy.

Results 38 (76.0\%) had injuries. 22 (44\%) had the round sternal skin lesions derived from the piston. Visceral injuries were found in 12 cases. 4 had abdominal injuries. Eight patients had thoracic injuries only. The most common visceral injuries were lung contusions and heart contusion. Contrary to 